\title{
The MC4R SNPs, their haplotypes and gene- environment interactions on the risk of obesity
}

\author{
Bi-Liu Wei ${ }^{1}$, Rui-Xing Yin ${ }^{1,2,3^{*}}$ (D), Chun-Xiao Liu', Guo-Xiong Deng ${ }^{1}$, Yao-Zong Guan ${ }^{1}$ and Peng-Fei Zheng ${ }^{1}$
}

\begin{abstract}
Background: Little is known about the correlation between the melanocortin 4 receptor gene (MC4R) single nucleotide polymorphisms (SNPs) and the risk of obesity. This research sought to test the MC4R rs17782313, rs476828 and rs12970134 SNPs, their haplotypes and gene-environment interactions on the risk of obesity in the Maonan ethnic group, an isolated minority in China.

Methods: A case-control study comprised of 1836 participants (obesity group, 858; and control group, 978) was conducted. Genotypes of the three SNPs were determined by the next-generation sequencing (NGS) technology.

Results: The genotypic frequencies of the three SNPs were different between the obesity and control groups $(P<0.05$ for all). The minor allelic frequency of the MC4R rs17782313C, rs476828C and rs12970134A was higher in obesity than in control groups $(13.8 \%$ vs. $8.3 \%, P<0.001,17.1 \%$ vs. $10.9 \%, P<0.001$; and $15.5 \%$ vs. $11.5 \%$,

$P<0.001$; respectively). Additionally, the dominant model of rs 17782313 and rs476828 SNPs revealed an increased morbidity function on the risk of obesity $(P<0.05)$. A correlation between SNP-environment and the risk of obesity was also observed. The rs17782313C-rs476828C-rs12970134A haplotype was associated with high risk of obesity $(\mathrm{OR}=1.796,95 \% \mathrm{Cl}=1.447-2.229)$, whereas the rs17782313T-rs476828T-rs12970134G and rs17782313T-rs476828Trs 12970134A haplotypes were associated with low risk of obesity $(\mathrm{OR}=0.699,95 \% \mathrm{Cl}=0.586-0.834$ and $\mathrm{OR}=0.620$, $95 \% \mathrm{Cl}=0.416-0.925$; respectively). The interactions between haplotype and waist circumference on the risk of obesity were also noted.

Conclusions: We discovered that the MC4R rs17782313, rs476828 and rs12970134 SNPs and their haplotypes were associated with the risk of obesity in the Chinese Maonan population.
\end{abstract}

Keywords: Melanocortin 4 receptor gene (MC4R), Single nucleotide polymorphism, Obesity, Environmental factor

\section{Introduction}

Obesity represents a serious global health problem (Doak et al. 2012). More than 0.4 billion people all over the world are obese based on the criteria designated by the World Health Organization. In addition, several

\footnotetext{
*Correspondence: yinruixing@163.com

'Department of Cardiology, Institute of Cardiovascular Diseases, the First Affiliated Hospital, Guangxi Medical University, 6 Shuangyong Road, Nanning, Guangxi 530021, People's Republic of China

${ }^{2}$ Guangxi Key Laboratory Base of Precision Medicine in

Cardio-cerebrovascular Disease Control and Prevention, Nanning, Guangxi

530021, People's Republic of China

Full list of author information is available at the end of the article
}

studies have suggested that obesity is associated with increased risks of type 2 diabetes, cardiovascular disease and hypertension (Dixon 2010).

Obesity is a complex disease that is modified by an interaction between genetic and environmental factors (Xi et al. 2011). Recent research on the genetic elements that place individuals at risk of obesity has uncovered several contributing factors. A genome-wide association study (GWAS) from 2008 reported that the melanocortin 4 receptor gene $(M C 4 R)$ was associated with obesity (Loos et al. 2008). Another study found that the rs17782313 polymorphism, located near the $M C 4 R$, is

(c) The Author(s). 2020 Open Access This article is licensed under a Creative Commons Attribution 4.0 International License, which permits use, sharing, adaptation, distribution and reproduction in any medium or format, as long as you give appropriate credit to the original author(s) and the source, provide a link to the Creative Commons licence, and indicate if changes were made. The images or other third party material in this article are included in the article's Creative Commons licence, unless indicated otherwise in a credit line to the material. If material is not included in the article's Creative Commons licence and your intended use is not permitted by statutory regulation or exceeds the permitted use, you will need to obtain permission directly from the copyright holder. To view a copy of this licence, visit http://creativecommons.org/licenses/by/4.0/. 
linked to corpulency in European adults and children (Loos et al. 2008). Two polymorphisms (rs12970134 and rs476828) near the $M C 4 R$ have also been associated with increased risk of obesity in Europeans and Europeans, respectively (Thorleifsson et al. 2009; Grant et al. 2009). Additionally, several research papers have also demonstrated MC4R variability across different ethnic groups (Grant et al. 2009; Hotta et al. 2009; Tabara et al. 2009; Cauchi et al. 2009; Renstrom et al. 2009; Zobel et al. 2009; Meyre et al. 2009; Willer et al. 2009; Cheung et al. 2010; Shi et al. 2010; Huang et al. 2011; Rouskas et al. 2012; Beckers et al. 2011; Thomsen et al. 2012; Tao et al. 2012; Liem et al. 2010; Wu et al. 2010; Vogel et al. 2011; Ng et al. 2010), although some studies fail to demonstrate any significant correlation (Grant et al. 2009; Hotta et al. 2009; Tabara et al. 2009; Liem et al. 2010; $\mathrm{Ng}$ et al. 2010). The differences may be owed to the modest impact of polymorphism, the limited statistical ability of small sample sizes, and the discrepancy in the genetic and environmental factors of the study subjects.

China has 56 ethnic groups. According to the statistics of the sixth national census in 2010, Han Chinese represents the largest population. The Maonan nationality is a minority group of Southeastern China and consists of approximately 107,166 people. The closest anthropological cousins of the Maonan are the Buyi ethnic group (Ogata et al. 2007). In Guangxi, the genetic correlation between the Maonan population and other minorities is much higher than that between the Maonan and Han (Deng et al. 2007; Yao et al. 2009). A previous study has demonstrated that the three MC4R (rs17782313, rs12970134 and rs476828) SNPs have an impact on obesity, but their relationship to the risk of obesity has yet to be clearly outlined. Therefore, the objective of this research was to determine the relationship between the three MC4R SNPs, their respective interactions with the environment and the obese phenotype in the Maonan people. Our research utilizes the multi-dimensional dimensionality reduction (MDR) method to analyze the correlation between the MC4R SNPs based on haplotype clustering and gene $\times$ environment $(\mathrm{G} \times \mathrm{E})$ interactions on obesity in the Maonan population.

\section{Materials and methods \\ SNP selection}

Three SNPs of MC4R were chosen by the following steps: (1) They were tagging SNPs identified by Haploview (Broad Institute or MIT and Harvard, Cambridge, MA, USA, version 4.2). (2) MC4R rs17782313, rs476828 and rs12970134 SNPs were then selected by SHEsis Main (http://analysis.bio-x.cn/myAnalysis.php). (3) The minor allele frequency (MAF) of the SNPs was more than $1 \%$. (4) The SNPs may be potentially associated with obesity in the previous researches. (5) Related data of the SNPs could be gained from NCBI dbSNP Build 132 (http://www.ncbi.nlm.nih.gov/SNP/).

\section{Subjects}

This is a case-control study (Batarfi et al. 2019) and a total of 1836 Maonan individuals which were previously included in stratified stochastic specimens were randomly selected (Guo et al. 2016). All individuals were living in the Huanjiang Maonan Autonomous County, which is located in Northwestern Guangxi Zhuang Autonomous Region of China. The individuals' age ranged from 18 to 90 (mean $55.38 \pm 15.33$ ) years in controls. Ages <40, 40-49, 50-59, 60-69, 70-79 and $\geq 80$ years were 155 (15.8\%), 206 (21.1\%), 209 (21.4\%), 196 (20.0\%), $158(16.2 \%)$ and 54 (5.5\%) people; respectively. The participants' age ranged from 22 to 90 (mean $56.29 \pm 14.25$ ) years in patients with obesity. Ages <40, 40-49, 50-59, $60-69, \quad 70-79$ and $\geq 80$ years were 132 (15.4\%), 184 (21.4\%), 186 (21.7\%), 171 (19.9\%), 139 (16.2\%) and 46 (5.4\%) persons; respectively. The selection criteria for Maonan individuals have been described in detail in two previous epidemiological studies (Wang et al. 2016; Bin et al. 2017). In addition, all Maonan subjects were also confirmed by Y chromosome and mitochondrial diversity studies. All individuals were healthy, they had no evidence of related diseases such as diabetes, atherosclerosis, and coronary heart disease. The participants were also not on any medications known to influence obesity. The sample size was calculated using QUANTO software (http://hydra.usc.edu/gxe) (Wang and Li 2004). All people in the participating population gave written informed consent to participate in epidemiological investigations and genetic analysis. All research protocols on this topic have been approved by the Ethics Committee of the First Affiliated Hospital of Guangxi Medical University (No. Lunshen-2014 KY-Guoji-001, Mar. 7, 2014).

\section{Epidemiologic investigation}

The epidemiologic investigation used international standardization methods and an established study protocol (Zhang et al. 2017). The study used standardized questionnaires to collect information regarding demographics, socioeconomic status, and lifestyle factors. Smoking or drinking status was designated into either one of two groups (yes or no) (Li et al. 2018). The research also incorporated several parameters to measure blood pressure, waist circumference (WC) and other clinical procedures. Body mass index (BMI, $\mathrm{kg} / \mathrm{m}^{2}$ ) was calculated based on preexisting formulas.

\section{Biochemical measurements}

All participants fasted for at least $12 \mathrm{~h}$ prior to venous blood sampling. The values of total cholesterol (TC), triglyceride (TG), high-density lipoprotein (HDL-C), and 
low-density lipoprotein cholesterol (LDL-C) in specimens were measured using commercially available enzyme assay kits, CHOL2 for TC, TRIGL for TG, HDLC4 for HDL-C, and LDLC3 for LDL-C (Roche Diagnostics GmbH., Sandhofer Strasse 116, 68,305 Mannheim, Germany). The detected ranges of TC, TG, HDL-C and LDL-C were $0.1-20.7,0.1-10.0,0.08-3.88$ and $0.10-$ $14.2 \mathrm{mmol} / \mathrm{L}$ or $3.86-800,8.85-885,3.09-150$ and $3.87-$ $549 \mathrm{mg} / \mathrm{dL}$, respectively. Furthermore, the detection limits of the CHOL2, TRIGL, HDLC4 and LDLC3 Kits were $0.1 \mathrm{mmol} / \mathrm{L}, 0.1,0.08$ and $0.1 \mathrm{mmol} / \mathrm{L}$, or 3.86 , $8.85,3.09$ and $3.87 \mathrm{mg} / \mathrm{dL}$, respectively, which are the lowest measurable analyte level (different from zero). The intra-batch precision of the assay kits was 21. An autoanalyzer (Type cobas c 701/702; Roche Diagnostics GmbH., Sandhofer Strasse 116, 68,305 Mannheim, Germany) was used to perform all determinations in the Clinical Science Experiment Center of the First Affiliated Hospital, Guangxi Medical University (Aung et al. 2014).

\section{Diagnostic criterion}

The normal values of TC, TG, HDL-C and LDL-C in our Clinical Science Experiment Center were 3.10-5.17, $0.56-1.70,1.16-1.42$ and $2.70-3.10 \mathrm{mmol} / \mathrm{L}$, respectively. One or more of the following conditions were used to define dyslipidemia: $\mathrm{LDL}-\mathrm{C} \geq 3.6 \mathrm{mmol} / \mathrm{l} ; \mathrm{TG} \geq 1.7$ $\mathrm{mmol} / \mathrm{l} ; \quad \mathrm{HDL}-\mathrm{C}<1.29 \mathrm{mmol} / \mathrm{l}$ in women or $<1.03$ $\mathrm{mmol} / \mathrm{l}$ in men; TC $\geq 5.7 \mathrm{mmol} / \mathrm{l}$, basing on the NECPATP III criteria (Zhang et al. 2012; Grundy et al. 2006). Hyperlipidemia depended on $\mathrm{TC}>5.17 \mathrm{mmol} / \mathrm{L}$, and/or TG $>1.70 \mathrm{mmol} / \mathrm{L}$ (Wu et al. 2016). Hypertension was determined when the participants have a systolic blood pressure of $140 \mathrm{mmHg}$ or greater, and/or a diastolic blood pressure of $90 \mathrm{mmHg}$ or higher (Chalmers et al. 1999). Participants were separated into two groups, according to age $>60$ or $\leq 60$. WC was defined as $\geq 90 \mathrm{~cm}$ for men or $\geq 80 \mathrm{~cm}$ for women subgroups (Grundy et al. 2006; Saely et al. 2006). A BMI of $<23$ and $\geq 25 \mathrm{~kg} / \mathrm{m}^{2}$ was determined as control and obesity (Wen et al. 2009); respectively.

\section{DNA amplification and genotyping}

Genomic DNA was separated from leucocytes of venous blood using the phenol-chloroform method (Miao et al. 2018). All separated DNA samples were stored at $4{ }^{\circ} \mathrm{C}$ until further analysis. Genotyping of the three SNPs was accomplished by next-generation sequencing technology in the NGS department, Sangon Biotech (Shanghai) Co; Ltd. (1) Sense and antisense primers: the sense and antisense primers used were 5 '-TCCACATGCTATTGGTTT AAGACAAGTC-3' and 5' -TCCCAGATGCTAAAATGA TACTCCTCAATA-3' for the rs17782313; 5'-ACTTCT TAGTCTGGCTGTCAACAAAC-3' 5' -CCCTTGGAGT AGCAATTGGAAG-3' for the rs476828; and 5'-GAGA
CTGGCAAAGCAGAGTTTT-3' and 5'-CCTTTGAATA CAGGTACTAACAAGCAC-3' for the rs12970134; respectively. (2) Multiplex PCR and sequencing: A panel which contains 3 target SNPs (rs17782313, rs476828 and rs12970134) was designed. Library preparation was performed by two-step PCR. First round PCR reaction was set up: DNA (10 ng/ $\mu \mathrm{l}) 2 \mu \mathrm{l}$; amplicon PCR forward primer mix $(10 \mu \mathrm{M}) 1 \mu \mathrm{l}$; amplicon PCR reverse primer mix $(10 \mu \mathrm{M}) 1 \mu \mathrm{l} ; 2 \times$ PCR Ready Mix $15 \mu \mathrm{l}$ (total $25 \mu \mathrm{l}$, Kapa HiFi Ready Mix). The plate was sealed and PCR performed in a thermal instrument (BIO-RAD, T100TM) using the following program: 1 cycle of denaturing at $98^{\circ} \mathrm{C}$ for 5 min, first 8 cycles of denaturing at $98^{\circ} \mathrm{C}$ for $30 \mathrm{~s}$, annealing at $50{ }^{\circ} \mathrm{C}$ for $30 \mathrm{~s}$, elongation at $72^{\circ} \mathrm{C}$ for $30 \mathrm{~s}$, then 25 cycles of denaturing at $98^{\circ} \mathrm{C}$ for $30 \mathrm{~s}$, annealing at $66^{\circ} \mathrm{C}$ for $30 \mathrm{~s}$, elongation at $72{ }^{\circ} \mathrm{C}$ for $30 \mathrm{~s}$ and a final extension at $72^{\circ} \mathrm{C}$ for $5 \mathrm{~min}$. Finally hold at $4{ }^{\circ} \mathrm{C}$. The PCR products were checked using electrophoresis in $1 \%(\mathrm{w} / \mathrm{v})$ agarose gels in TBE buffer (Tris, boric acid, EDTA) stained with ethidium bromide (EB) and visualized under UV light. Then we used AMPure XP beads to purify the amplicon product. After that, the second round PCR was performed. PCR reaction was set up: DNA (10 ng/ $\mu \mathrm{l}) 2 \mu \mathrm{l}$; universal P7 primer with barcode $(10 \mu \mathrm{M}) 1 \mu$; universal P5 primer $(10 \mu \mathrm{M}) 1 \mu \mathrm{l} ; 2 \times$ PCR Ready Mix $15 \mu \mathrm{l}$ (total $30 \mu \mathrm{l}$, Kapa HiFi Ready Mix). The plate was sealed and PCR performed in a thermal instrument (BIO-RAD, T100TM) using the following program: 1 cycle of denaturing at $95^{\circ} \mathrm{C}$ for 3 min, then 5 cycles of denaturing at $94^{\circ} \mathrm{C}$ for $30 \mathrm{~s}$, annealing at $55^{\circ} \mathrm{C}$ for $20 \mathrm{~s}$, elongation at $72^{\circ} \mathrm{C}$ for $30 \mathrm{~s}$, elongation at $72{ }^{\circ} \mathrm{C}$ for $30 \mathrm{~s}$ and a final extension at $72^{\circ} \mathrm{C}$ for 5 min. Then we used AMPure XP beads to purify the amplicon product. The libraries were then quantified and pooled. Paired-end sequencing of the library was performed on the HiSeq XTen sequencers (Illumina, San Diego, CA). (3) Data QC and SNP calling: raw reads were filtered according to two steps: 1 ) removing adaptor sequence if reads contains by cutadapt (v 1.2.1); 2) removing low quality bases from reads $3^{\prime}$ to $5^{\prime}(\mathrm{Q}<20)$ by PRIN SEQ-lite(v 0.20.3); and the remaining clean data were mapped to the reference genome by BWA (version 0.7.13r1126) with default parameters. A perl script was written to calculate each genotype of target site. Annovar (201804-16) was used to detect genetic variants.

\section{Statistical analyses}

The data was statistically analyzed using the statistical software SPSS 22.0 (SPSS Inc., Chicago, IL, USA). Normally distributed quantitative data were expressed in terms of mean $\pm \mathrm{SD}$, whereas TG for non-normally distributed data was represented in terms of medians and interquartile ranges. Qualitative data was presented in terms of percentage and was analyzed using the Chisquare test between the obesity and control groups. 
Table 1 Comparison of general characteristics between control and obesity groups

\begin{tabular}{|c|c|c|c|c|}
\hline Parameter & Control & Obesity & $t\left(x^{2}\right)$ & $P$ \\
\hline Number & 978 & 858 & & \\
\hline Age $\left(\right.$ years) ${ }^{a}$ & $55.38 \pm 15.33$ & $56.29 \pm 14.25$ & -1.323 & 0.186 \\
\hline Body mass index $\left(\mathrm{kgm}^{2}\right)$ & $20.01 \pm 1.48$ & $27.62 \pm 3.07$ & -66.13 & $<0.001$ \\
\hline Waist circumference $(\mathrm{cm})$ & $71.51 \pm 6.487$ & $87.52 \pm 8.14$ & -46.264 & $<0.001$ \\
\hline Systolic blood pressure (mmHg) & $131.49 \pm 23.28$ & $137.83 \pm 22.79$ & -5.88 & $<0.001$ \\
\hline Diastolic blood pressure $(\mathrm{mmHg})$ & $80.64 \pm 12.36$ & $85.57 \pm 13.67$ & -8.063 & $<0.001$ \\
\hline Glucose (mmol/L) & $6.17 \pm 1.37$ & $6.24 \pm 1.32$ & -1.283 & 0.200 \\
\hline $\mathrm{TC}(\mathrm{mmol} / \mathrm{L})$ & $4.89 \pm 0.98$ & $5.09 \pm 0.93$ & -4.607 & $<0.001$ \\
\hline $\mathrm{TG}(\mathrm{mmol} / \mathrm{L})^{\mathrm{b}}$ & $1.17(0.93)$ & $1.63(1.22)$ & -14.095 & $<0.001$ \\
\hline $\mathrm{HDL}-\mathrm{C}(\mathrm{mmol} / \mathrm{L})$ & $1.30 \pm 0.29$ & $1.25 \pm 0.26$ & 3.792 & $<0.001$ \\
\hline $\mathrm{LDL}-\mathrm{C}(\mathrm{mmol} / \mathrm{L})$ & $3.10 \pm 0.45$ & $3.18 \pm 0.50$ & -3.695 & $<0.001$ \\
\hline Male/female ${ }^{c}$ & $450 / 528$ & $395 / 463$ & 0.000 & 0.991 \\
\hline \multicolumn{5}{|l|}{ Smoking status [n (\%)] } \\
\hline Non-smoker & 772 (78.9) & $637(74.2)$ & & \\
\hline Smoker & $206(21.1)$ & $221(25.8)$ & 5.643 & 0.018 \\
\hline \multicolumn{5}{|l|}{ Alcohol consumption [n (\%)] } \\
\hline Non-drinker & 795 (81.3) & $686(80.0)$ & & \\
\hline Drinker & $183(18.7)$ & $172(20.0)$ & 0.522 & 0.470 \\
\hline
\end{tabular}

The student's unpaired $t$-test was used to test the general characteristics which are normally distributed between two groups. The difference in TG levels between the two groups was detected by the Wilcoxon-MannWhitney test. Analysis of genotype, allele and haplotype distribution between two groups was tested by the chi- squared test. The Hardy-Weinberg equilibrium (HWE), Pair-wise linkage disequilibrium (LD) and frequencies of haplotype were calculated by the SHEsis Main software (http://analysis.bio-x.cn/myAnalysis.php) (Shi and He 2005). Using the SHEsis software, $D^{\prime}$ and $r^{2}$ were used to detect pair-wise LD patterns between selected

Table 2 The correlation between the MC4R polymorphisms and the risk of obesity [n (\%)]

\begin{tabular}{|c|c|c|c|c|c|c|c|}
\hline$\overline{S N P}$ & Genotype & $\begin{array}{l}\text { Control } \\
(n=978)\end{array}$ & $\begin{array}{l}\text { Obesity } \\
(n=858)\end{array}$ & $x^{2}$ & $P$ & $\begin{array}{l}\text { Adjusted OR } \\
(95 \% \mathrm{Cl})\end{array}$ & ${ }^{*} P$ \\
\hline \multirow[t]{4}{*}{ rs17782313 T > C } & $\pi$ & $823(84.2)$ & $633(73.8)$ & 29.974 & $<0.001$ & 1 & - \\
\hline & $\mathrm{CT}+\mathrm{CC}$ & $155(15.8)$ & $225(26.2)$ & & & $1.428(1.066-2.061)$ & 0.019 \\
\hline & MAF & $163(8.3)$ & 237 (13.8) & 28.258 & $<0.001$ & & \\
\hline & $P_{\mathrm{HWE}}$ & 0.613 & 0.210 & & & & \\
\hline \multirow[t]{4}{*}{ rs476828 T > C } & $\pi$ & $780(79.8)$ & $582(67.8)$ & 33.921 & $<0.001$ & 1 & - \\
\hline & $\mathrm{CT}+\mathrm{CC}$ & $198(20.2)$ & $276(32.2)$ & & & $1.585(1.176-2.136)$ & 0.003 \\
\hline & MAF & $213(10.9)$ & $293(17.1)$ & 29.431 & $<0.001$ & & \\
\hline & $P_{\mathrm{HWE}}$ & 0.262 & 0.053 & & & & \\
\hline \multirow[t]{4}{*}{ rs12970134 G > A } & GG & $765(78.2)$ & $606(70.6)$ & 13.927 & $<0.001$ & 1 & - \\
\hline & $A G+A A$ & $213(21.8)$ & $252(29.4)$ & & & $1.253(0.924-1.698)$ & 0.147 \\
\hline & MAF & $224(11.5)$ & $266(15.5)$ & 12.961 & $<0.001$ & & \\
\hline & $P_{\text {HWE }}$ & 0.565 & 0.085 & & & & \\
\hline
\end{tabular}


variants. Unconditional logic regression was used to test both the correlation of genotypes (common homozygote genotype $=1$, heterozygote genotype $=2$, rare homozygote genotype $=3$ ), alleles (the minor allele non-carrier $=1$, the minor allele carrier $=2$ ) and haplotypes (the haplotype non-carrier $=1$, the haplotype carrier $=2$ ) with the risk hazard of obesity, but also the SNP- or haplotype- environment interactions on the risk hazard of obesity after gender, age, WC, smoking, alcohol consumption, hypertension and hyperlipidemia were adjusted ( $\mathrm{Li}$ et al. 2018; Miao et al. 2018). Related risks were evaluated by odds ratio (OR) and $95 \%$ confidence interval $(95 \% \mathrm{CI})$, and $P<0.05$ was regarded as statistical significance. The best interactive combination between the SNPs, haplotypes and environmental factors (WC, age, smoking, drinking and sex) was screened by generalized multifactor dimensionality reduction (GMDR) (Lou 2015; Lou et al. 2007), which is a free, open-source interaction analysis tool. It is enriched in options for detecting gene-gene and gene-environment interaction in different design, such as case-control design. For case-control design, by default, GMDR can detect interactions for unrelated individuals. The GMDR software is entirely available at website (http:// www.soph.uab.edu/ssg/software or http://ibi.zju.edu.cn/ software) (Xu et al. 2016). The cross-validation consistency score (also known as 10-fold crossvalidation) is a method of measuring the degree of consistency of the selected interactions, and the result is expressed in $\mathrm{N} 1 / \mathrm{N} 2$ ( $\mathrm{N}$ ranges from 1 to 10 ) (Miao et al. 2018; Lin et al. 2013). Among all the possibilities considered, the selected interactions were determined as the best model. Test balance accuracy is a measure of the degree of interaction that accurately estimates case-control status, with a score between 0.50
Table 3 Degree of linkage disequilibrium between the MC4R SNPs and the combined population of obesity and control groups

\begin{tabular}{llll}
\hline$r^{2}$ & rs17782313 & rs476828 & rs12970134 \\
\hline rs17782313 & 1 & & \\
rs476828 & 0.765 & 1 & 1 \\
rs12970134 & 0.711 & 0.524 & 1 \\
\hline
\end{tabular}

(indicating that the model predicts worse than chance) and 1.00 (indicating perfect prediction) (Miao et al. 2018; Lin et al. 2013). Finally, a sign test or permutation test of the prediction accuracy (providing empirical $P$ values) can be used to estimate the signification of the recognition model (Miao et al. 2018; Lin et al. 2013).

\section{Results}

Demographical characteristics of study population

Demographical parameters of the 1836 study subjects are summarized in Table 1 . The mean values of BMI, WC, systolic blood pressure (SBP), diastolic blood pressure (DBP), TC, TG and LDL-C levels and the percentages of subjects who smoked cigarettes were higher while HDL-C value was lower in obese patients compared to the control subjects $(P<0.05-0.001)$. However, no discrepancies were noted in terms of age structure, glucose levels, sex ratio, and drinking between the two groups $(P>0.05$ for all).

\section{Genotype and allele frequencies and their respective associations with obesity}

As shown in Table 2, the genotype and minor allele frequencies of the rs17782313, rs476828 and rs12970134 SNPs were different between the obesity and control groups $(P<0.05)$. All mutations exhibited HWE $(P>0.05$

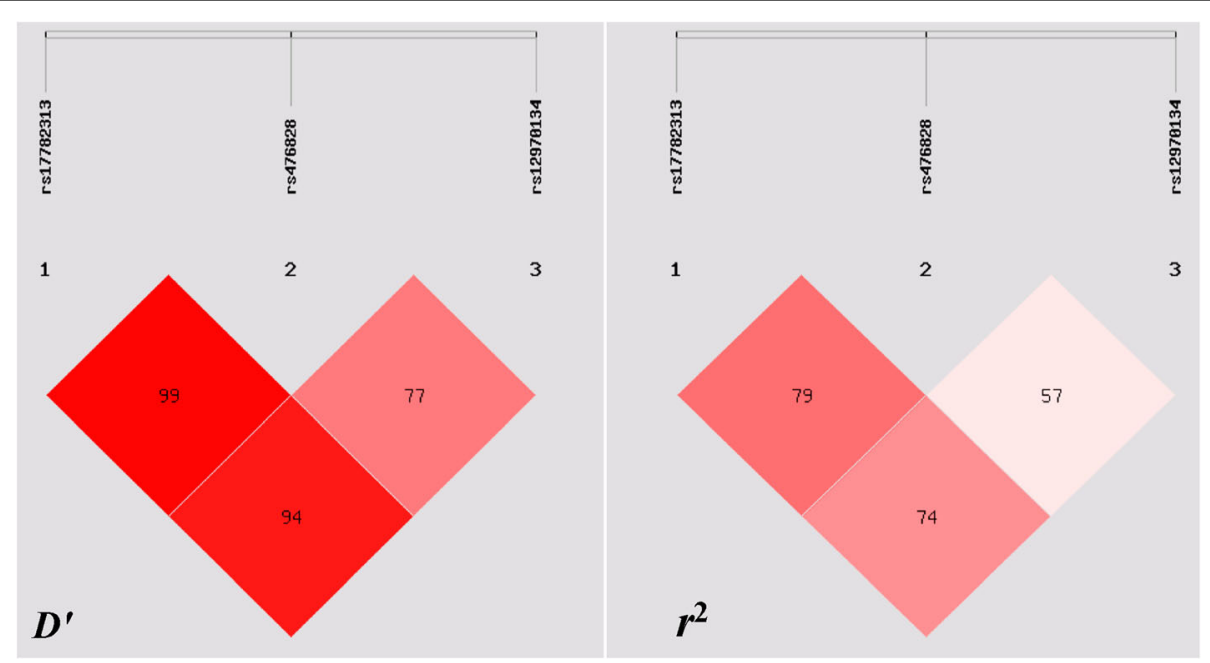

Fig. 1 Linkage disequilibrium (LD) analysis of the MC4R SNPs in both populations. The LD degree was represented by pair-wise $D^{\prime}$ and $r^{2}$ 
Table 4 Prevalence of haplotype frequencies in the obesity and control groups [ $n$ (frequency)]

\begin{tabular}{llllll}
\hline Haplotype & Obesity & Control & $x^{2}$ & $P$ & OR (95\% Cl) \\
\hline C-C-A & $227.77(0.133)$ & $153.67(0.079)$ & 28.845 & $<0.001$ & $1.796[1.447-2.229]$ \\
C-C-G & $9.23(0.005)$ & $9.31(0.005)$ & - & - & - \\
T-C-A & $0.00(0.000)$ & $1.01(0.001)$ & - & - & - \\
T-C-G & $56.00(0.033)$ & $48.99(0.025)$ & 1.896 & 0.168458 & $1.313[0.890-1.938]$ \\
T-T-A & $38.23(0.022)$ & $69.32(0.035)$ & 5.570 & 0.018294 & $0.620[0.416-0.925]$ \\
T-T-G & $1384.77(0.807)$ & $1673.67(0.856)$ & 15.946 & $<0.001$ & $0.699[0.586-0.834]$
\end{tabular}

The haplotype is combined with MC4R rs17782313-rs476828-rs12970134. Rare Hap (frequency < 3\%) in both groups has been ignored in analysis

for all). At the same time, the morbidity functions of the rs17782313 and rs476828 SNPs were increased in the dominant model $(P<0.05)$, whereas there was no statistical significance in the dominant mode of rs12970134 SNP $(P>0.05)$.

\section{Haplotypes and the risk of obesity}

Multiple-locus LD analyses indicated that the tested sites in the study population were not statistically independent. Table 3 and Fig. 1 show strong LD between control and obesity groups $\left(D^{\prime}=0.72-0.99\right)$. As shown in Table 4, the commonest haplotypes were T-T-G, C-C-A and T-T-A ( $>30 \%$ of the samples). There were significant differences in the frequency of T-T-G, C-C-A and T-T-A haplotypes between the obesity and control groups. In the meantime, conservations of the T-T-G, C-C-A and T-T-A haplotypes were observed, whereas the $\mathrm{C}$-C-A haplotype contributed to an increased morbidity function $(P<0.05)$.

\section{SNP and haplotype-environment interaction on the risk of obesity}

The influence of gene-environment exposures including the interactions between SNPs, age, gender, BMI, WC, tobacco and/or alcohol consumption on obesity risk was analyzed by the GMDR model, after adjustment for covariates. Table 5 summarizes the results obtained from the GMDR analysis for two- to three-locus models for gene-environment interaction. A significant three-locus model $(P<0.001)$ involving rs12970134 SNP, drinking and WC was found, indicating a potential interaction between SNPs and these environmental factors. In the meantime, this model had a cross-validation consistency of 10 of 10 , with a testing accuracy of $82.56 \%$ (Miao et al. 2018; Lin et al. 2013). Moreover, the three-locus model also tested haplotype-environment interactions (WC, drinking and T-T-A, $P<0.001$ ). An entropy-based interaction dendrogram built by MDR is shown in Fig. 2, which revealed the strongest redundancy effect in the SNPenvironment interaction (rs12970134 and WC) and in the haplotype-environment interaction (WC and T-T-A). In order to acquire the OR and 95\%CI for the combined effects, we performed an interaction study using logistic regression analyses (Table 6). When the SNP-environment interaction was analyzed, we revealed that the participants with rs12970134 GA/AA genotypes and WC (male $\geq 90 \mathrm{~cm}$ or female $\geq 80 \mathrm{~cm}$ ) had higher risk of obesity compared to the participants with rs12970134 GG and WC (male <90 $\mathrm{cm}$ or female $<80 \mathrm{~cm}$; adjusted $\mathrm{OR}=95.069,95 \% \mathrm{CI}=$ 47.260-191.351, $P<0.001)$. In addition, when the haplotype-environment interactions were studied, we detected that the carriers of T-T-A haplotype and WC (male $\geq 90 \mathrm{~cm}$ or female $\geq 80 \mathrm{~cm}$ ) had higher obesity risk than the non-carriers and WC (male $\geq 90 \mathrm{~cm}$ or female $\geq 80 \mathrm{~cm}$; adjusted OR $=51.533,95 \% \mathrm{CI}=12.131-218.912, P<0.001)$.

\section{Discussion}

Obesity is a known contributor towards cardiovascular illness and premature mortality (Peeters et al. 2003; Jimenez et al. 2018). The occurrence of obesity

Table 5 GMDR analysis of SNPs, haplotype and environment showed different interactions

\begin{tabular}{|c|c|c|c|c|c|c|}
\hline Locus no. & Best combination & $\begin{array}{l}\text { Training } \\
\text { Bal. Acc }\end{array}$ & $\begin{array}{l}\text { Testing } \\
\text { Bal. Acc }\end{array}$ & $\begin{array}{l}\text { Cross-validation } \\
\text { consistency }\end{array}$ & $P$ & ${ }^{*} P$ \\
\hline \multicolumn{7}{|c|}{ SNP-environment interaction } \\
\hline 2 & $W C+$ Age & 0.8213 & 0.8213 & $10 / 10$ & $<0.001$ & $<0.001$ \\
\hline 3 & WC+ drinking+ rs 12970134 & 0.8256 & 0.8256 & $10 / 10$ & $<0.001$ & $<0.001$ \\
\hline \multicolumn{7}{|c|}{ Haplotype-environment interaction } \\
\hline 2 & WC+ Age & 0.8213 & 0.8213 & $10 / 10$ & $<0.001$ & $<0.001$ \\
\hline 3 & $W C+$ drinking + T-T-A & 0.8232 & 0.8232 & $10 / 10$ & $<0.001$ & $<0.001$ \\
\hline
\end{tabular}

$P$, adjusting for sex, age, smoking, drinking, hypertension, hyperlipidemia, waist circumference (WC), and impaired fasting glucose. ${ }^{*} P$, indicates 1000 permutation tests. The haplotype is combined with MC4R rs17782313-rs476828-rs12970134 


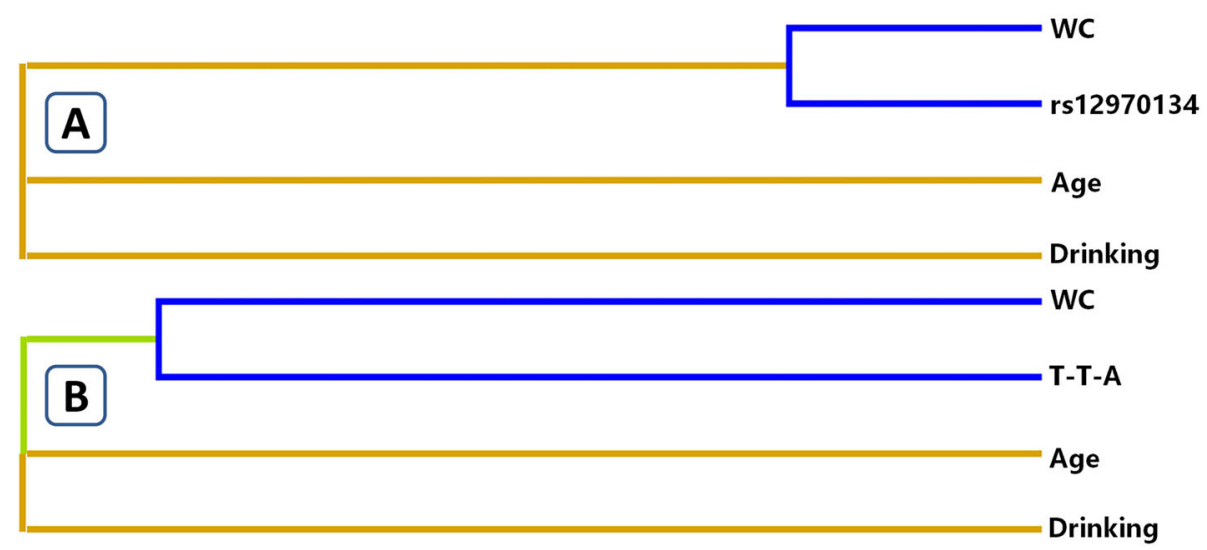

Fig. 2 Different types of interaction dendrogram for SNP-environment (a) and haplotype-environment (b) interactions on the risk of obesity. Blue color, strong redundancy interaction; green color, weak redundancy interaction; orange color, synergy. The elements with strong interaction are close to each other at the leaves of tree, and the elements with weak interaction are far away from each other

is the product of interaction between a variety of environmental factors, such as diet, unhealthy lifestyle, lack of exercise as well as genetic factors (Xi et al. 2011; Unamuno et al. 2018; Teixeira et al. 2016). Biologically active mediators which are released by adipose tissue have a significant impact on weight, insulin resistance as well as changes in blood pressure and lipid levels, all of which result in endothelial dysfunction and atherosclerosis.

Current research has identified an association between the MC4R mutations and obesity. The genotypic and allelic frequencies of three MC4R SNPs were significantly different between the obesity and control participants. These outcomes strongly suggest that the prevalence of obesity may stem from genetic elements. Upon closer observation of the relationship between the MC4R SNPs and their haplotypes and the risk of obesity, we noted that the rs17782313C-rs476828Crs12970134A haplotype increased the risk of obesity. Conversely, the rs17782313T-rs476828T-rs12970134G and rs17782313T-rs476828T-rs12970134A haplotypes were associated with decreased risk of obesity. At the same time, we also found that the participants with the rs12970134 GA/AA genotypes and WC (male $\geq 90 \mathrm{~cm}$ or female $\geq 80 \mathrm{~cm}$; SNP-environment interaction) had higher risk of obesity than the individuals with rs12970134 GG and WC (male $<90 \mathrm{~cm}$ or female $<80 \mathrm{~cm}$ ). The carriers of T-T-A haplotype and WC (male $\geq 90 \mathrm{~cm}$ or female $\geq 80$ $\mathrm{cm}$; haplotype-environment interaction) had higher risk of obesity than the haplotype non-carriers and WC (male $\geq 90 \mathrm{~cm}$ or female $\geq 80 \mathrm{~cm}$ ). These observations underscore the strong role of genetic influences in the development of obesity (Unamuno et al. 2018; Teixeira et al. 2016; Ruixing et al. 2008).

Table 6 Using logistic regression to analyze different types of interactions

\begin{tabular}{|c|c|c|c|}
\hline Variable 1 & Variable 2 & OR $(95 \% \mathrm{Cl})$ & $P$ \\
\hline \multicolumn{4}{|c|}{ SNP-environment interaction } \\
\hline rs12970134 & $W C$ (male $\geq 90 \mathrm{~cm}$, female $\geq 80 \mathrm{~cm}$ ) & & \\
\hline GG & No & 1 & - \\
\hline GG & Yes & $42.577(28.714-63.132)$ & $<0.001$ \\
\hline$G A+A A$ & No & $1.07(0.758-1.51)$ & 0.701 \\
\hline $\mathrm{GA}+\mathrm{AA}$ & Yes & $95.096(47.260-191.351)$ & $<0.001$ \\
\hline \multicolumn{4}{|c|}{ Haplotype-environment interaction } \\
\hline T-T-A & $W C$ (male $\geq 90 \mathrm{~cm}$, female $\geq 80 \mathrm{~cm}$ ) & & \\
\hline Non-carriers & No & 1 & - \\
\hline Non-carriers & Yes & $51.371(40.001-65.972)$ & $<0.001$ \\
\hline Carriers & No & $0.503(0.246-1.027)$ & 0.059 \\
\hline Carriers & Yes & $51.533(12.131-218.912)$ & $<0.001$ \\
\hline
\end{tabular}

$P$, adjusting for sex, age, smoking, drinking, hypertension, hyperlipidemia, and impaired fasting glucose. T-T-A is combined with MC4R rs17782313-rs476828-rs12970134 
The Maonan diet consists of large proportions of pork, animal viscus and beef, all of which are rich in saturated fatty acid (Miao et al. 2018). High-fat diets are significant contributors of obesity, dyslipidemia (especially raised plasma TC and TG levels (Lottenberg et al. 2012), atherosclerosis, and hypertension (Teixeira et al. 2016; Ruixing et al. 2008) which may explain the differences in the prevalence of hypertension, plasma TC and TG levels between the two groups at present. The percentages of subjects who consumed alcohol and smoked cigarettes were high amongst the Maonan adult population, the percentages of cigarette smoking were significantly different between the obesity and control groups, whereas there was no significant difference in the percentages of alcohol consumption between the two groups. The effects of alcohol consumption and cigarette smoking on obesity have previously been studied (Gruchow et al. 1985; Fulkerson and French 2003; Audrain-McGovern and Benowitz 2011; Seeley and Sandoval 2011; Rigotti and Clair 2018). Most smokers are underweight, and quitting smoking often leads to being overweight or obesity (Fulkerson and French 2003; Audrain-McGovern and Benowitz 2011; Seeley and Sandoval 2011; Rigotti and Clair 2018). However, several different observational studies on alcohol consumption and smoking have yielded contradictory results, warranting further investigations involving different cohorts, ethnicities and age groups across different populations (Sayon-Orea et al. 2011; Bendsen et al. 2013). Several GWASes have uncovered genetic variants that are associated to different aspects of general wellbeing. However, it is sometimes overlooked that the genetic variations found in GWAS may represent the effects of modifiable hazardous elements as well as direct genetic influences (Gage et al. 2016). Our research sought to dissect this possibility by using examples of patients who partake in high fat diets or those who had high alcohol and cigarette usage.

Our research has several limitations. Firstly, the importance of several other genetic and environmental elements cannot be discounted, for example, energy intake, physical activity and dietary patterns. Secondly, the sample size of this research is relatively small and should be expanded. Finally, obesity is undoubtedly a complex and multifactorial illness (Chooi et al. 2019). Although our studies have tested the correlation of three MC4R SNPs and their haplotypes to the risk of obesity, several other gene-environment interactions still need to be measured.

\section{Conclusions}

In summary, our study investigated the potential interactions between the MC4R SNPs, environment and obesity in the Maonan population. Moreover, the correlation analysis based on haplotype clustering and $\mathrm{G} \times \mathrm{E}$ interactions may be more informative regarding the risk of obesity in contrast to single-locus tests. GMDR analysis demonstrated several different interactions that exist between gene and environment that may be able to impact patient morbidity.

\section{Abbreviations}

BMI: Body mass index; Cl: Confidence interval; DBP: Diastolic blood pressure; GMDR: Generalized multifactor dimensionality reduction; GWAS: Genomewide association study; HDL-C: High-density lipoprotein cholesterol; HWE: Hardy-Weinberg equilibrium; LD: Linkage disequilibrium; LDL-C: Lowdensity lipoprotein cholesterol; MAF: Minor allele frequency; MC4R: Melanocortin 4 receptor; NGS: Next-generation sequencing; OR: Odds ratio; SBP: Systolic blood pressure; SNP: Single nucleotide polymorphism; TC: Total cholesterol; TG: Triglyceride; WC: Waist circumference

\section{Acknowledgments}

The authors would like to acknowledge all the participants of this study and the staff from the Guangxi Key Laboratory Base of Precision Medicine in Cardio-Cerebrovascular Disease Control and Prevention.

\section{Authors' contributions}

B.-L.W. conceived the study, participated in the design, undertook genotyping, performed the statistical analyses, and drafted the manuscript. R.-X.Y. conceived the study, participated in the design, carried out the epidemiological survey, collected the samples, and helped to draft the manuscript. C.-X.L. collaborated to the genotyping. G.-X.D., Y.-Z.G. and P.-F.Z. carried out the epidemiological survey and collected the samples. All authors read and approved the final manuscript.

\section{Funding}

This work was supported by the National Natural Science Foundation of China (No: 81460169).

\section{Ethics approval and consent to participate}

The research was conducted in accordance with the rules of the 1975 Helsinki Declaration ((http://www.wma.net/en/30publications/10policies/b3/), revised in 2008). All people in the participating population gave written informed consent to participate in epidemiological investigations and genetic analysis. All research protocols on this topic have been approved by the Ethics Committee of the First Affiliated Hospital of Guangxi Medical University (No. Lunshen-2014 KY-Guoji-001, Mar. 7, 2014).

\section{Consent for publication}

All authors agree to publish this article in the journal of Molecular Medicine.

\section{Competing interests}

The authors declare no competing interests.

\section{Author details}

'Department of Cardiology, Institute of Cardiovascular Diseases, the First Affiliated Hospital, Guangxi Medical University, 6 Shuangyong Road, Nanning, Guangxi 530021, People's Republic of China. ${ }^{2}$ Guangxi Key Laboratory Base of Precision Medicine in Cardio-cerebrovascular Disease Control and Prevention, Nanning, Guangxi 530021, People's Republic of China. ${ }^{3}$ Guangxi Clinical Research Center for Cardio-cerebrovascular Diseases, Nanning, Guangxi 530021, People's Republic of China.

Received: 17 April 2020 Accepted: 21 July 2020

Published online: 08 August 2020

\section{References}

Audrain-McGovern J, Benowitz NL. Cigarette smoking, nicotine, and body weight Clin Pharmacol Ther. 2011:90(1):164-8.

Aung LH, Yin RX, Wu DF, Wang W, Liu CW, Pan SL. Association of the variants in the BUD13-ZNF259 genes and the risk of hyperlipidaemia. J Cell Mol Med. 2014; 18(7):1417-28.

Batarfi AA, Filimban N, Bajouh OS, Dallol A, Chaudhary AG, Bakhashab S. MC4R variants rs12970134 and rs17782313 are associated with obese polycystic 
ovary syndrome patients in the Western region of Saudi Arabia. BMC Med Genet. 2019;20(1):144.

Beckers S, Zegers D, de Freitas F, Mertens IL, Van Gaal LF, Van Hul W. Association study of MC4R with complex obesity and replication of the rs17782313 association signal. Mol Genet Metab. 2011;103(1):71-5.

Bendsen NT, Christensen R, Bartels EM, Kok FJ, Sierksma A, Raben A, Astrup A. Is beer consumption related to measures of abdominal and general obesity? A systematic review and meta-analysis. Nutr Rev. 2013;71(2):67-87.

Bin Y, Meng E-J, Ya Y-X, Yin R-X, Liu W-Y, Zhang L, Li K-L, Wu J-Z, Lin W-X, Li H. Prevalence, awareness, treatment, control and the risk factors of hypertension in the Chinese Maonan and Han ethnic groups. Int J Clin Exp Med. 2017;10(1):1209-23.

Cauchi S, Stutzmann F, Cavalcanti-Proenca C, Durand E, Pouta A, Hartikainen AL, Marre M, Vol S, Tammelin T, Laitinen J, Gonzalez-Izquierdo A, Blakemore AI, et al. Combined effects of MC4R and FTO common genetic variants on obesity in European general populations. J Mol Med (Berl). 2009;87(5):537-46.

Chalmers J, MacMahon S, Mancia G, Whitworth J, Beilin L, Hansson L, Neal B, Rodgers A, Ni Mhurchu C, Clark T. 1999 World Health OrganizationInternational Society of Hypertension Guidelines for the management of hypertension. Guidelines sub-committee of the World Health Organization. Clin Exp Hypertens. 1999;21(5-6):1009-60.

Cheung CY, Tso AW, Cheung BM, Xu A, Ong KL, Fong CH, Wat NM, Janus ED, Sham PC, Lam KS. Obesity susceptibility genetic variants identified from recent genome-wide association studies: implications in a Chinese population. J Clin Endocrinol Metab. 2010;95(3):1395-403.

Chooi YC, Ding C, Magkos F. The epidemiology of obesity. Metab Clin Exp. 2019; 92:6-10.

Deng Q, Xu L, Gong J, Zhou L, Li S, Deng X, Luo G, Xie X. Genetic relationships among four minorities in Guangxi revealed by analysis of 15 STRs. J Genet Genomics. 2007;34(12):1072-9.

Dixon JB. The effect of obesity on health outcomes. Mol Cell Endocrinol. 2010; 316(2):104-8.

Doak CM, Wijnhoven TM, Schokker DF, Visscher TL, Seidell JC. Age standardization in mapping adult overweight and obesity trends in the WHO European region. Obes Rev. 2012;13(2):174-91.

Fulkerson JA, French SA. Cigarette smoking for weight loss or control among adolescents: gender and racial/ethnic differences. J Adolesc Health. 2003; 32(4):306-13.

Gage SH, Smith GD, Ware JJ, Flint J, Munafo MR. Correction: G = E: what GWAS can tell us about the environment. PLoS Genet. 2016;12(5):e1006065.

Grant SF, Bradfield JP, Zhang H, Wang K, Kim CE, Annaiah K, Santa E, Glessner JT, Thomas K, Garris M, Frackelton EC, Otieno FG, et al. Investigation of the locus near MC4R with childhood obesity in Americans of European and African ancestry. Obesity (Silver Spring). 2009;17(7):1461-5.

Gruchow HW, Sobocinski KA, Barboriak JJ, Scheller JG. Alcohol consumption, nutrient intake and relative body weight among US adults. Am J Clin Nutr. 1985;42(2):289-95.

Grundy SM, Cleeman JI, Daniels SR, Donato KA, Eckel RH, Franklin BA, Gordon DJ, Krauss RM, Savage PJ, Smith SC Jr, Spertus JA, Costa F. Diagnosis and management of the metabolic syndrome: an American Heart Association/ National Heart, Lung, and Blood Institute scientific statement. Curr Opin Cardiol. 2006;21(1):1-6.

Guo T, Yin RX, Lin WX, Wang W, Huang F, Pan SL. Association of the variants and haplotypes in the DOCK7, PCSK9 and GALNT2 genes and the risk of hyperlipidaemia. J Cell Mol Med. 2016;20(2):243-65.

Hotta K, Nakamura M, Nakamura T, Matsuo T, Nakata Y, Kamohara S, Miyatake N, Kotani K, Komatsu R, Itoh N, Mineo I, Wada J, et al. Association between obesity and polymorphisms in SEC16B, TMEM18, GNPDA2, BDNF, FAIM2 and MC4R in a Japanese population. J Hum Genet. 2009;54(12):727-31.

Huang W, Sun Y, Sun J. Combined effects of FTO rs9939609 and MC4R rs17782313 on obesity and BMI in Chinese Han populations. Endocrine. 2011; 39(1):69-74.

Jimenez MP, Green MA, Subramanian SV, Razak F. A demographic, clinical, and behavioral typology of obesity in the United States: an analysis of National Health and Nutrition Examination Survey 2011-2012. Ann Epidemiol. 2018; 28(3):175-81.e4.

Li WJ, Yin RX, Cao XL, Chen WX, Huang F, Wu JZ. DOCK7-ANGPTL3 SNPs and their haplotypes with serum lipid levels and the risk of coronary artery disease and ischemic stroke. Lipids Health Dis. 2018;17(1):30.

Liem ET, Vonk JM, Sauer PJ, van der Steege G, Oosterom E, Stolk RP, Snieder H. Influence of common variants near INSIG2, in FTO, and near MC4R genes on overweight and the metabolic profile in adolescence: the TRAILS (TRacking Adolescents' Individual Lives Survey) study. Am J Clin Nutr. 2010;91(2):321-8.

Lin Z, Su Y, Zhang C, Xing M, Ding W, Liao L, Guan Y, Li Z, Cui D. The interaction of BDNF and NTRK2 gene increases the susceptibility of paranoid schizophrenia. PLoS One. 2013;8(9):e74264.

Loos RJ, Lindgren CM, Li S, Wheeler E, Zhao JH, Prokopenko I, Inouye M, Freathy RM, Attwood AP, Beckmann JS, Berndt SI, Jacobs KB, et al. Common variants near MC4R are associated with fat mass, weight and risk of obesity. Nat Genet. 2008;40(6):768-75.

Lottenberg AM, Afonso Mda S, Lavrador MS, Machado RM, Nakandakare ER. The role of dietary fatty acids in the pathology of metabolic syndrome. J Nutr Biochem. 2012;23(9):1027-40.

Lou XY. UGMDR: a unified conceptual framework for detection of multifactor interactions underlying complex traits. Heredity (Edinb). 2015;114(3):255-61.

Lou XY, Chen GB, Yan L, Ma JZ, Zhu J, Elston RC, Li MD. A generalized combinatorial approach for detecting gene-by-gene and gene-byenvironment interactions with application to nicotine dependence. Am J Hum Genet. 2007;80(6):1125-37.

Meyre D, Delplanque J, Chevre JC, Lecoeur C, Lobbens S, Gallina S, Durand E, Vatin V, Degraeve F, Proenca C, Gaget S, Korner A, et al. Genome-wide association study for early-onset and morbid adult obesity identifies three new risk loci in European populations. Nat Genet. 2009;41(2):157-9.

Miao L, Yin RX, Pan SL, Yang S, Yang DZ, Lin WX. BCL3-PVRL2-TOMM40 SNPS, gene-gene and gene-environment interactions on dyslipidemia. Sci Rep. 2018;8(1):6189.

Ng MC, Tam CH, So WY, Ho JS, Chan AW, Lee HM, Wang Y, Lam VK, Chan JC, Ma RC. Implication of genetic variants near NEGR1, SEC16B, TMEM18, ETV5/ DGKG, GNPDA2, LIN7C/BDNF, MTCH2, BCDIN3D/FAIM2, SH2B1, FTO, MC4R, and KCTD15 with obesity and type 2 diabetes in 7705 Chinese. J Clin Endocrinol Metab. 2010;95(5):2418-25.

Ogata S, Shi L, Matsushita M, Yu L, Huang XQ, Shi L, Sun H, Ohashi J, Muramatsu M, Tokunaga K, Chu JY. Polymorphisms of human leucocyte antigen genes in Maonan people in China. Tissue Antigens. 2007;69(2):154-60.

Peeters A, Barendregt JJ, Willekens F, Mackenbach JP, Al Mamun A, Bonneux L. Obesity in adulthood and its consequences for life expectancy: a life-table analysis. Ann Intern Med. 2003;138(1):24-32.

Renstrom F, Payne F, Nordstrom A, Brito EC, Rolandsson O, Hallmans G, Barroso I, Nordstrom P, Franks PW. Replication and extension of genome-wide association study results for obesity in 4923 adults from northern Sweden. Hum Mol Genet. 2009;18(8):1489-96.

Rigotti NA, Clair C. Weight gain after smoking cessation: more data to refute concerns. Eur Heart J. 2018;39(17):1532-4.

Rouskas K, Kouvatsi A, Paletas K, Papazoglou D, Tsapas A, Lobbens S, Vatin V, Durand E, Labrune Y, Delplanque J, Meyre D, Froguel P. Common variants in FTO, MC4R, TMEM18, PRL, AIF1, and PCSK1 show evidence of association with adult obesity in the Greek population. Obesity (Silver Spring). 2012;20(2):389-95.

Ruixing $Y$, Jinzhen $W$, Yaoheng $H$, Jing $T$, Hai W, Muyan $L$, Yiyang $L$, Dongmei $F$, Hanjun $Y$, Yuming C. Associations of diet and lifestyle with hyperlipidemia for middle-aged and elderly persons among the Guangxi Bai Ku Yao and Han populations. J Am Diet Assoc. 2008;108(6):970-6.

Saely CH, Koch L, Schmid F, Marte T, Aczel S, Langer P, Hoefle G, Drexel H. Adult treatment panel III 2001 but not international diabetes federation 2005 criteria of the metabolic syndrome predict clinical cardiovascular events in subjects who underwent coronary angiography. Diabetes Care. 2006;29(4): 901-7.

Sayon-Orea C, Martinez-Gonzalez MA, Bes-Rastrollo M. Alcohol consumption and body weight: a systematic review. Nutr Rev. 2011;69(8):419-31.

Seeley RJ, Sandoval DA. Neuroscience: weight loss through smoking. Nature. 2011;475(7355):176-7

Shi J, Long J, Gao YT, Lu W, Cai Q, Wen W, Zheng Y, Yu K, Xiang YB, Hu FB, Zheng W, Shu XO. Evaluation of genetic susceptibility loci for obesity in Chinese women. Am J Epidemiol. 2010;172(3):244-54.

Shi YY, He L. SHEsis, a powerful software platform for analyses of linkage disequilibrium, haplotype construction, and genetic association at polymorphism loci. Cell Res. 2005;15(2):97-8.

Tabara Y, Osawa H, Guo H, Kawamoto R, Onuma H, Shimizu I, Takara Y, Nishida W, Yamamoto M, Makino H, Kohara K, Miki T. Prognostic significance of FTO genotype in the development of obesity in Japanese: the J-SHIPP study. Int Obes. 2009;33(11):1243-8.

Tao L, Zhang Z, Chen Z, Zhou D, Li W, Kan M, Zhang D, He L, Huang G, Liu Y. A common variant near the melanocortin 4 receptor is associated with low- 
density lipoprotein cholesterol and total cholesterol in the Chinese Han population. Mol Biol Rep. 2012;39(6):6487-93.

Teixeira AA, Lira FS, Pimentel GD, Oliveira de Souza C, Batatinha H, Biondo LA, Yamashita AS, Junior EA, Neto JC. Aerobic exercise modulates the free fatty acids and inflammatory response during obesity and cancer cachexia. Crit Rev Eukaryot Gene Expr. 2016;26(3):187-98.

Thomsen M, Dahl M, Tybjaerg-Hansen A, Nordestgaard BG. beta2-adrenergic receptor Thr164lle polymorphism, obesity, and diabetes: comparison with FTO, MC4R, and TMEM18 polymorphisms in more than 64,000 individuals. J Clin Endocrinol Metab. 2012;97(6):E1074-9.

Thorleifsson G, Walters GB, Gudbjartsson DF, Steinthorsdottir V, Sulem P, Helgadottir A, Styrkarsdottir U, Gretarsdottir S, Thorlacius S, Jonsdottir I, Jonsdottir T, Olafsdottir EJ, et al. Genome-wide association yields new sequence variants at seven loci that associate with measures of obesity. Nat Genet. 2009:41(1):18-24.

Unamuno X, Gomez-Ambrosi J, Rodriguez A, Becerril S, Fruhbeck G, Catalan V. Adipokine dysregulation and adipose tissue inflammation in human obesity. Eur J Clin Investig. 2018;48(9):e12997.

Vogel Cl, Boes T, Reinehr T, Roth CL, Scherag S, Scherag A, Hebebrand J, Hinney A. Common variants near MC4R: exploring gender effects in overweight and obese children and adolescents participating in a lifestyle intervention. Obes Facts. 2011;4(1):67-75

Wang Y, Aung LH, Tan JY, Yin RX, Hu XJ, Long XJ, Wu DF, Miao L, Yang DZ, Pan SL. Prevalence of dyslipidemia and its risk factors in the Chinese Maonan and Han populations. Int J Clin Exp Pathol. 2016;9(10):10603-16.

Wang ZP, Li HQ. Sample size requirements for association studies on gene-gene interaction in case-control study. Zhonghua Liu Xing Bing Xue Za Zhi. 2004; 25(7):623-6.

Wen CP, David Cheng TY, Tsai SP, Chan HT, Hsu HL, Hsu CC, Eriksen MP. Are Asians at greater mortality risks for being overweight than Caucasians? Redefining obesity for Asians. Public Health Nutr. 2009;12(4):497-506.

Willer CJ, Speliotes EK, Loos RJ, Li S, Lindgren CM, Heid IM, Berndt SI, Elliott AL, Jackson AU, Lamina C, Lettre G, Lim N, et al. Six new loci associated with body mass index highlight a neuronal influence on body weight regulation. Nat Genet. 2009;41(1):25-34.

Wu DF, Yin RX, Cao XL, Huang F, Wu JZ, Chen WX. MADD-FOLH1 polymorphisms and their haplotypes with serum lipid levels and the risk of coronary heart disease and ischemic stroke in a Chinese Han population. Nutrients. 2016; 8(4):208.

Wu L, Xi B, Zhang M, Shen Y, Zhao X, Cheng H, Hou D, Sun D, Ott J, Wang X, Mi $J$. Associations of six single nucleotide polymorphisms in obesity-related genes with BMI and risk of obesity in Chinese children. Diabetes. 2010;59(12): 3085-9.

Xi B, Wang C, Wu L, Zhang M, Shen Y, Zhao X, Wang X, Mi J. Influence of physical inactivity on associations between single nucleotide polymorphisms and genetic predisposition to childhood obesity. Am J Epidemiol. 2011; 173(11):1256-62.

Xu HM, Xu LF, Hou TT, Luo LF, Chen GB, Sun XW, Lou XY. GMDR: versatile software for detecting gene-gene and gene-environment interactions underlying complex traits. Curr Genomics. 2016;17(5):396-402.

Yao Y, Shi L, Shi L, Lin K, Yu L, Sun H, Huang X, Tao Y, Yi W, Liu S, Chu J. The association between HLA-A, $-B$ alleles and major histocompatibility complex class I polymorphic Alu insertions in four populations in China. Tissue Antigens. 2009;73(6):575-81.

Zhang J, Fan P, Liu H, Bai H, Wang Y, Zhang F. Apolipoprotein A-I and B levels, dyslipidemia and metabolic syndrome in south-west Chinese women with PCOS. Hum Reprod. 2012;27(8):2484-93.

Zhang QH, Yin RX, Gao H, Huang F, Wu JZ, Pan SL, Lin WX, Yang DZ. Association of the SPTLC3 rs364585 polymorphism and serum lipid profiles in two Chinese ethnic groups. Lipids Health Dis. 2017;16(1):1.

Zobel DP, Andreasen CH, Grarup N, Eiberg H, Sorensen TI, Sandbaek A, Lauritzen T, Borch-Johnsen K, Jorgensen T, Pedersen O, Hansen T. Variants near MC4R are associated with obesity and influence obesity-related quantitative traits in a population of middle-aged people: studies of 14,940 Danes. Diabetes. 2009; 58(3):757-64.

\section{Publisher's Note}

Springer Nature remains neutral with regard to jurisdictional claims in published maps and institutional affiliations.

Ready to submit your research? Choose BMC and benefit from:

- fast, convenient online submission

- thorough peer review by experienced researchers in your field

- rapid publication on acceptance

- support for research data, including large and complex data types

- gold Open Access which fosters wider collaboration and increased citations

- maximum visibility for your research: over $100 \mathrm{M}$ website views per year

At BMC, research is always in progress.

Learn more biomedcentral.com/submissions 